\title{
Mesenchymal Stem Cells in Mesangial Repair in a Model of Immunoglobulin Light Chain-Mediated Mesangial Injury
}

\author{
Guillermo A Herrera ${ }^{1,2 *}$, Jiamin Teng ${ }^{1}$, Xin Liu ${ }^{4}$, Yanping Zhang ${ }^{5}$ and Elba A Turbat-Herrera ${ }^{1-3}$ \\ ${ }^{1}$ Department of Pathology, Louisiana State University Health Sciences Center, Shreveport, Louisiana 71103, USA \\ ${ }^{2}$ Department of Cellular Biology and Anatomy, Louisiana State University Health Sciences Center, Shreveport, Louisiana 71103, USA \\ ${ }^{3}$ Department of Obstetrics and Gynecology, Louisiana State University Health Sciences Center, Shreveport, Louisiana 71103, USA \\ ${ }^{4}$ Departments of Pathology, Saint Louis University, St. Louis, Missouri 63104, USA \\ ${ }^{5}$ Departments of Surgery, Saint Louis University, St. Louis, Missouri 63104, USA
}

\begin{abstract}
Mesangial injury produced by glomerulopathic monoclonal immunoglobulin light chains leads to two diametrically opposed results: matrix loss from mesangiolysis / replacement of mesangial matrix with amyloid (AL-amyloidosis) and increased matrix (light chain deposition disease), depending on the physicochemically abnormal light chains involved. In both situations; however, there is loss of mesangial cells resulting from apoptosis induced by the glomerulopathic light chains.

This unique experimental model of mesangial injury resulting in divergent manifestations allows examining the role of mesenchymal stem cells in mesangial glomerular repair in the two typical prototypes of alterations that occur in the mesangium when injured by a variety of injurious agents.

In vitro and ex vivo platforms are used to translate information from the in-vitro to the in-vivo arenas. Both platforms highlight the same sequence of events that take place: mesenchymal stem cells identify the site of damage, clear the damaged mesangium by eliminating debris from apoptotic cellular elements and deposited "foreign" (not belonging in the normal mesangium) material and eventually differentiate into mature mesangial cells laying down new matrix.

Each of the platforms employed exhibited certain advantages and limitations in visualizing and understanding the processes that occur. When the information generated was combined, a clear view of mechanisms involved and how mesenchymal stem cells participated in mesangial repair emerged.
\end{abstract}

Keywords: Mesenchymal stem cells; Stem cells; Mesangial repair; AL-amyloidosis; Light chain deposition disease; Mesangium; Mesangial cells; Mesangial matrix

\section{Introduction}

Some glomerular diseases center their pathologic manifestations in the mesangium, either in their initial phases or as they evolve into chronicity, where progressive damage results in irreversible events leading to glomerulosclerosis. This is the case with glomerulopathic light chains (LCs) which because of their peculiar physicochemical composition and conformation are able to interact with receptors located at the cellular membranes of mesangial cells (MCs) and produce pathological alterations [1-4]. Some diseases may also have concomitant peripheral capillary wall alterations, but the mesangial pathology is crucial for their initiation, development and progression. The targets of the injurious agents in these diseases are the MCs and surrounding matrix.

Diseases with mesangiocentric pathology include nodular diabetic glomerulosclerosis, the most common glomerulopathy associated with a systemic disorder which is also characterized by excess production of mesangial matrix by MCs via activation of transforming growth factor- $\beta$ [5], reproducing the pathology seen in light chain deposition disease (LCDD) and thrombotic microangiopathy where mesangiolysis resulting from activation of metalloproteinases is a key pathologic event similar to what occurs in AL (light chain-related) amyloidosis [6]. While controlling the injurious agent is crucial to avoid repetitive and/or continuous renal damage, once damage has occurred, fixing the mesangial alterations becomes important to improve renal function and avoid the inevitable progressive damage that results in end-stage renal disease, ultimately requiring dialysis or transplantation with their expected management challenges and complications.
The mesangium is in constant turnover and is carefully maintained structurally and biochemically intact by the interaction of a number of growth factors and related effector molecules that working in concert effectively maintain homeostasis [7-10]. There are a number of additional "built-in" processes that may come to the rescue when the mesangium is slightly injured. Data has been generated (which to some is still controversial) reflecting a contribution of the bone marrow stem cells to normal or to reactive glomerular turnover, even to encompass certain glomerular disease processes. MCs can quickly proliferate after injury or simply as a reactive process to non-glomerular pathology. Nevertheless, the glomerulus has a limited capacity for repair.

Sugimoto et al. demonstrated that transplantation of wild type bone marrow into irradiated COL4 A3 -/- mice resulted in recruitment of bone marrow cells which then differentiated as podocytes and MCs leading to partial restoration of type IV collagen $\alpha 3$ chain and concomitant emergence of $\alpha 4$ and $\alpha 5$ chain expression repairing the basement membrane defect and improving renal function

*Corresponding author: Guillermo A. Herrera MD, 1541 Kings Highway, Shreveport, Louisiana, 71103, USA, Tel: 318-675-5878; Fax: 318-675-4541; E-mail: gherr1@Isuhsc.edu

Received May 19, 2014; Accepted July 14, 2014; Published July 16, 2014

Citation: Herrera GA, Teng J, Liu X, Zhang Y, Turbat-Herrera EA (2014) Mesenchymal Stem Cells in Mesangial Repair in a Model of Immunoglobulin Light Chain-Mediated Mesangial Injury. J Stem Cell Res Ther 4: 215. doi:10.4172/21577633.1000215

Copyright: @ 2014 Herrera GA, et al. This is an open-access article distributed under the terms of the Creative Commons Attribution License, which permits unrestricted use, distribution, and reproduction in any medium, provided the original author and source are credited. 
[11]. Prodromidi et al. showed that bone marrow-derived cells can differentiate into podocytes and MCs [12].

However, when homeostasis is disturbed by severe or chronic deleterious glomerular processes, the repair mechanisms activated to maintain normal MC turnover and matrix in the face of slightly abnormal circumstances are not sufficient and the mesangial injury cannot be effectively healed. While the therapeutic value of hematopoietic stem cells in renal repair remains dubious for a number of reasons [13,14], several studies have demonstrated a beneficial effect of mesenchymal stem cell administration in models of acute tubular and endothelial damage.

In addition, studies have also shown the presence of resident progenitor stem cells in the kidney [15-28]. There are niches of renal stem cells located in the medulla, in the interstitium proper / tubular epithelium, and along Bowman's capsule in the glomeruli, all capable to participate in repair activities. Which one of these niches become involved in glomerular repair remains somewhat unclear, though the progenitor cells located along Bowman's capsule are by far the best candidates. There is experimental evidence to support that progenitor cells along Bowman's capsule are able to replace podocytes in vitro and in vivo $[29,30]$. Progenitor cells are CD24, CD133, CK-7 and 9, bcl2, vimentin, MYOF (regeneration promoting molecule), OCT 4 (stem cell transcription factor) and PAX 2 positive $[16,23,27,28]$.

Several investigators have shown a beneficial effect of endothelial progenitor cells (EPC) in the treatment of acute experimental glomerulonephritis [31-34]. Endothelial progenitor cells derived from bone marrow and injected in rats with experimental anti-Thy nephritis promoted the recovery from glomerular injury and increased revascularization by integrating themselves in the endothelium lining glomerular capillaries. These stem cells induced a faster recovery from anti-Thy-1 glomerulonephritis and an increased production of VEGF and TGF-B $[35,36]$.

The work presented in this manuscript provides evidence that MSCs can play a crucial role in repairing the damaged mesangium in a unique experimental model of mesangial injury that recapitulates mesangial alterations that typically occur in glomerulopathies of various etiologies.

\section{Materials and Methods}

\section{Isolation and purification of immunoglobulin LCs obtained from the urine}

Free LCs were purified from the urine of patients with renal biopsyproven AL-amyloidosis $(\mathrm{n}=6)$ and LCDD $(\mathrm{n}=4)$ LCs (glomerulopathic LCs), and myeloma cast nephropathy $(\mathrm{MCN})(\mathrm{n}=3)$ LCs (tubulopathicTLCs). Ammonium sulfate was added to the urine to achieve $70 \%$ saturation. The precipitate was redissolved in distilled water and dialyzed at least 24 hours using cellulose dialysis tubing (Spectra/Por Membrane Tubing, Fisher Scientific, Pittsburgh, PA) with a 12,000 to 14,000 dalton cutoff, against distilled water and then in a $0.01 \mathrm{M}$ sodium phosphate buffer, pH 7.6 [37]. The urine was then spun in a tip ending centrifuge bottle to get rid of the debris. The supernatant was filtered through $0.2 \mu \mathrm{m}$ membrane and centrifuge with $300 \mathrm{KD}$ MWCO membranes (Pall Life Sciences, Port Washington, NY). The material recovered was centrifuged and the part obtained in the $<300$ $\mathrm{KD}$ portion was concentrated using a $3 \mathrm{KD}$ MWCO membrane and then dialyzed with a 3500 MWCO membrane.

Following the above procedures, the material obtained was run in an SDS gel and the LCs was identified by molecular weight. Purified LCs migrated as a single band when resolved by zone electrophoresis on agarose gels using $50 \mathrm{mmol} / \mathrm{L}$ barbital buffers, $\mathrm{pH}$ 8.6. The corresponding LCs consisted entirely of free $\kappa$ or $\lambda$ LCs, as determined by immunofixation. In some instances, dimers of lambda LCs were also identified.

A protein assay was run to determine the protein concentration. A penicillin-streptomycin solution (100X) (Sigma, Aldrich, St. Louis, Missouri) was added to avoid contamination. The purified LCs were then concentrated to $2 \mathrm{mg} / \mathrm{ml}$ dialyzed against $0.9 \% \mathrm{NaCl}$, filtered through a sterile $0.2 \mathrm{~mm}$ membrane, and stored aseptically in sealed vials at $4^{\circ} \mathrm{C}$. The LCs used for the various experiments were not pooled or combined in any fashion.

\section{Culture of MCs obtained from glomeruli}

Cortices of kidney obtained from nephrectomies for renal tumors away from the neoplastic lesions were minced and processed to isolate MCs following a well described protocol [38]. Rat MCs obtained from the kidneys of rats killed for the purpose of conducting experimental studies and MCs were isolated using the same protocol [38]. The cells were then cultured in RPMI 1640 medium containing 15\% fetal bovine serum maintained at $37^{\circ} \mathrm{C}$ in a humidified incubator containing $5 \%$ $\mathrm{CO}_{2}$. MCs overgrew epithelial cells and became confluent 3-4 weeks after plating. MCs were then trypsinized and transferred to the desired platforms for conducting the various experiments.

\section{Rat Mesenchymal Stem Cells (RMSCs)}

RMSC kits were purchased from Chemicon International (Temecula, California, USA). These cells were labeled with PKH2GL. Labeling of MSCs was performed by centrifuging $2 \times 10^{5} \mathrm{MCs}$ (per $35 \mathrm{~mm}$ Petri dish) at $400 \mathrm{~g}$ for 5 minutes into a pellet. The pellet was washed with PBS once and centrifuged again at $400 \mathrm{~g}$ for 5 minutes into a loose pellet. The pellet was then mixed with $1 \mathrm{ml}$ diluent $\mathrm{A}$ to insure complete dispersion.

A PKH2-GL stock solution was prepared immediately before staining by adding $2 \mu \mathrm{l}$ into $0.5 \mathrm{ml}$ of diluent A. Subsequently, a $0.5 \mathrm{ml}$ of $2 \mathrm{x}$ cells to $0.5 \mathrm{ml} 2 \mathrm{x}$ dyes was added in a $15 \mathrm{ml}$ tube, mixed completely by pipetting and incubating for 5 minutes periodically inverting the tube gently to assure complete mixing during the incubation. The staining process was then stopped by adding $1 \mathrm{ml} 1 \%$ BSA and the tube was incubated for another $1 \mathrm{~min}$. The serum-stopped sample was diluted with an equal volume of complete medium $(2 \mathrm{ml})$. Then the MSCs were centrifuged at $400 \mathrm{~g}$ for 10 minutes forming a pellet and an additional $1 \mathrm{ml}$ of medium was added. The cells were transferred into a new tube for further washing and this process was repeated 3 times. Cells were resuspended into the desired concentration. Finally, PKH2-GL was added along with the RMSCs into the coculture. This was followed by rapidly adding $0.5 \mathrm{ml}$ of $2 \mathrm{x}$ cells to $0.5 \mathrm{ml} 2 \mathrm{x}$ dyes in a $15 \mathrm{ml}$ tube and mixed completely by pipetting. Finally, incubation for $5 \mathrm{~min}$. was carried out periodically inverting the tube gently to assure complete mixing during the incubation.

\section{In vitro mesangial cell culture experiments}

Apoptosis determination in mesangial cells exposed to lcs using the modified annexin $\mathrm{v} /$ propidium iodide apoptosis assay: MCs grown on coverslips as monolayers were treated with glomerulopathic (GLCs) (LCDD and amyloidogenic) and TLCs, as well as without LCs. The finding of propidium iodide in nuclei of these MCs indicated the presence of apoptotic MCs. Observations were made at 15 and 30 minutes post-initial incubation with LCs. 
Six dimensional (6d) live cell in vitro cell culture system using research inverted system microscope for live cell imaging: The IX81 motorized inverted microscope system with fluorescence capabilities built for live cell imaging system (Olympus, Center Valley, Pennsylvania, USA) provided an exquisite platform for observing interactions of LCs with MCs in culture. These MCs were labeled with a number of fluorescence dyes to follow a variety of cellular processes activated by the glomerulopathic LCs such as apoptosis (caspase), phenotypic transformation (CD68, smooth muscle actin and smoothelin) and observing labeled MSCs as they participated in the repair process. This system was set up to take sequential photos of the MCs interacting with the LCs allowing a complete depiction of sequential mechanisms involved. At certain time points, MCs were retrieved and processed accordingly for evaluating results of various processes of interest. The $6 \mathrm{D}$ system was used to set up several predetermined areas or locations in the wells with experimental MCs in culture where the monitoring was to take place using $\mathrm{x}, \mathrm{y}$, and $\mathrm{z}$ coordinates, and to follow several fluorescence wavelength channels for fluorescence imaging. Photographs were taken at specific timeframes (10 to 15 to 30 minutes, as determined by specific experimental requirements).

Seeding of MCs into wells. Treatment with G and TLCs followed by introduction of MSCs: Cultured MCs $\left(1 \times 10^{5}\right)$ were seeded in 24 well plates on Matrigel membranes and incubated with $1 \mathrm{ml} \mathrm{RPMI}$ containing medium until confluent. The cells in culture were washed every 24 hours to get rid of dead cells and floating, non-attached cellular elements. The MCs were then made quiescent in 0.5\% FBS medium for 2 days. Cells were incubated with G and TLCs and after 4 days, MSCs were introduced into the wells, and the sequence of events that followed were monitored using the IX81 6D- live cell system.

Staining cells with lysotracker and lysosensor dyes: These stains were used to label MSCs to evaluate phagocytic activities associated with disposal of apoptotic MCs. For the LysoTracker (Carlsbad, California, USA) probe, a working concentration of 50-75 $\mathrm{nM}$ was used and for the LysoSensor probes (Carlsbad, California). The concentration used was $1 \mu \mathrm{M}$. The stock probe was diluted in phosphate buffer to achieve the desired concentrations. To reduce potential artifacts, the concentration of the dyes was kept as low as possible.

For cell suspensions, the samples were centrifuged to obtain cell pellets and subsequently the supernatant was aspirated. The cells were resuspended gently in prewarmed $\left(37^{\circ} \mathrm{C}\right)$ probe-containing medium and incubated for 30 minutes to 2 hours under appropriate growth conditions. The samples were re-pelleted by centrifugation, resuspended in fresh prewarmed medium, and evaluated using a fluorescence microscope fitted with the correct filters / channels for the appropriate wavelengths [39].

RMSCS cocultured with MCs treated with Glomerulopathic LCs with or without curcumin: Rat MCs were seeded at $1 \times 10^{4}$ concentration/well into a 24 wells plate and incubated to fluent and then were made quiescent by changing the $10 \%$ FBS to a $0.5 \%$ FBS medium. The MCs were then trypsinized, counted and stained using PKH2-GL as previously detailed. MCs were then treated with GLCs for 4 days with and without curcumin at $10 \mathrm{uM}$ and $20 \mathrm{uM}$ concentrations for different time frames to enhance apoptosis and to better visualize interactions between apoptotic MCs and RMSCs.

Different groups were tested including some with RMSCs only, one with rat MCs and curcumin only, and additional groups with a mixture of MCs and RMSCs with and without curcumin.

After treatment, the wells were washed with no serum medium twice. The labeled MSCs were then added into plates at a concentration of 5000 cells / well. Finally, the plates were monitored using the 6D system to observe events taking place for up to 14 days.

Immunofluorescence staining of MCs incubated with GLCs for caspase 3 using Magic Red as the fluorescence marker.

Expression of caspase 3 in MCs was used as an indicator of apoptosis. MCs incubated with LCDD and AL-LCs for up to 4 days were tested for caspase expression. Untreated MCs and MCs incubated with TLCs were used as controls. Caspase expression was detected and documented using the $6 \mathrm{D}$ live cell imaging system.

Immunofluorescence stains of MCs for CD68, smoothelin, and muscle specific antigen.

MCs treated as indicated above and collected at different time intervals, were stained using fluorescence labeled antibodies to CD68 (to identify macrophage differentiation- phenotype), and muscle specific actin and smoothelin (to detect smooth muscle differentiationphenotype) (Dako Co., Carpinteria, California, USA). The expression of these immunoreactants at different timeframes was followed with the $6 \mathrm{D}$ - live cell system.

Co-localization of MCs- PKH-Green with RMSC-lysotracker or ER-tracker. MCs incubated with GLCs and then with fluorescencelabeled RMSCs.

Rat MCs were made quiescent as previously described and then treated with LCs (amyloidogenic, LCDD and MCN-TLCs) for 4 days in a glass bottom 36 well plate. Afterwards, a concentration of $2 \times 107$ rat MSCs labeled with PKH26-GL (Sigma, St. Louis, MO, USA) are incubated with the previously treated MCs with 10\% FBS Fisher 344 MIX (50\% SCM015+50\%RPMI). The procured samples were then stained with CD68 and smoothelin using immunofluorescence. The labeled MSCs could also be followed sequentially as they identified the sites of injury, preceded with the repair process and differentiated afterwards.

\section{Ex Vivo kidney perfusion experiments}

Specifications for animals used in experiments: Munich-Wistar or Fisher-344 rat (Charles River, Wilmington, Massachusetts, USA), male or female, 10 to 12 weeks or 200-250 g BW and mice of Stock Cav tm1Mls/J or WT (JAX Mice, Bar Harbor, Maine, USA), male or female, 10-12 weeks or 200-250 g BW were used in the experiments.

Ex-Vivo kidney platform to observe glomeruli interacting with glomerulopathic lcs perfused through kidney artery: The perfusion chamber was used to maintain the perfused kidneys physiologically intact. Perfusion medium was enriched with $95 \%$ O2 and 5\% CO2 and the system temperature was maintained at $37^{\circ} \mathrm{C}$. A circulation pump maintained the renal artery pressure around $120-150 \mathrm{~mm}$ $\mathrm{Hg}$. Conductivity and $\mathrm{pH}$ sensors and a flow volume counter were connected to a recorder. The ureter was cannulated to obtain urine (sample collector). Excluding presurgical preparation of the animals and microsurgical vascular procedures, the perfusion courses varied from 3-96 hours according to the experimental design [40,41].

Animal care, anesthesia and surgical procedures: Animals were given $5 \%$ glucose water solution only the night before experiment to eliminate the intestine content to ensure easy operation next day. To reduce pain and distress to the animals to the minimum during the operation, anesthesia for both mice and rats was provided using ketamine $(40-80 \mathrm{mg} / \mathrm{kg}) /$ xylazine $(5-10 \mathrm{mg} / \mathrm{kg})$ and administered intraperitoneally. 
General surgical procedure: The surgical procedure is an extrapolation of the technique previously described for rats to mice, except that the small size of the animal required smaller instruments and performance of the surgical procedures under magnification. 50 IU/500 IU heparin sulphate was given intravenously to mouse/rat before operation. The anesthetized animal was placed on a heated board, and the rectal temperature was monitored with a probe and kept at $37^{\circ} \mathrm{C}$.

The abdominal wall was opened using a midline incision. The left ureter and urinary bladder outlet were ligated using a 6(0) silk suture as cannulation of the right ureter is technically difficult in mice, a polyethylene tube (PE-10) serving as a cannula was inserted into the urinary bladder and sutured in place to collect urine samples from right kidney. In the rat model, cannulation of the right ureter was also carried out with PE-10 tubing. The right renal artery was cannulated through the superior mesenteric artery. After blunt dissection of the superior mesenteric artery and separation from surrounding connective tissue, a 6(0) silk ligature was applied distally close to the mesentery. The proximal end was clamped using a micro vessel clip. A small incision is made in the superior mesenteric artery using iris scissors to allow cannulation with a $28 \mathrm{G}$ cannula. Flushing the clamped superior mesenteric artery with perfusate eliminated air bubbles. The superior mesenteric artery was then unclamped and the cannula was advanced across the aorta into the right renal artery without disruption of renal flow. The cannula was fixed in place using $6(0)$ silk sutures, one around the superior mesenteric artery and another around the right renal artery.

The right kidney, ureter (and urinary bladder in mouse model) were removed en bloc. The kidney was then suspended above a glass funnel to allow collection and recirculation of perfusate. The kidney was placed in the perfusion chamber and the artery catheter was connected with the perfusion system.

\section{Methodology for perfusing kidneys Ex vivo}

Control kidneys were perfused only with perfusate containing $0.5 \% \mathrm{FBS} / \mathrm{RPMI}$ while the experimental kidneys were perfused with $\mathrm{G}$ and TLCs for 3-96 hours and then with additional substances or cells, including Curcumin $10 \mu \mathrm{M}$ and MSCs, depending on the experiments to be performed. Prior to delivering stem cells though the renal artery, they were labeled with PKH-2 GL mixed with $1 \times 10^{6}$ rat MSCs. The perfusate was delivered in an hour. Repeated perfusions every 6 hours for 96 hours were performed.

Sample handling and evaluation: Samples were procured from renal cortices of the rat or mice kidneys perfused ex-vivo at various time frames accordingly and processed for light, immunofluorescence and transmission electron microscopic evaluation. Samples from the specimens incubated on Matrigel membranes were also obtained at various time frames for histological assessment. No immunofluorescence or ultrastructural evaluation was performed in the latter samples.

Light microscopy: Wedge shaped cortical renal tissue fragments from the ex-vivo perfusion experiments and MCs in culture grown on Matrigel were fixed in $10 \%$ formalin, embedded in paraffin, sectioned at $4 \mu \mathrm{m}$, placed on glass slides, and stained with hematoxylin and eosin, periodic acid Schiff (PAS), and silver methenamine following standards protocols. Sections were viewed using a BX41 Olympus light microscope (Center Valley, Pennsylvania, USA). In addition, sections were cut at 8-10 um for Congo red and thioflavin T stains for amyloid detection. While the stained Congo red sections were viewed with the light microscope and subsequently polarized, thioflavin $\mathrm{T}$ sections were examined with a microscope with fluorescence capabilities (BX41 Olympus microscope, Center Valley, Pennsylvania, USA).

Immunofluorescence studies: Wedge shaped cortical renal tissue fragments from the specimens obtained from ex-vivo experiments were placed on Michels solution and later frozen and sectioned in a cryostat at $4 \mathrm{um}$. They were then stained with a direct fluorescence method using fluorescein isothiocyanate and polyclonal antibodies to kappa and lambda LCs (DAKO Co., Carpinteria, California, USA). Specimens were evaluated using a BX41 Olympus microscope (Center Valley, Pennsylvania, USA) with fluorescence capabilities.

\section{Transmission electron microscopy protocol}

Cortical areas of the kidneys obtained from the ex-vivo perfused kidneys were cut into $1 \mathrm{~mm}$ cubes. The tissue cubes were fixed for at least 2 hours in glutaraldehyde (Ted Pella, Inc., Redding, California) at room temperature.

The specimens were then rinsed 3 times in an appropriate buffer for 5 minutes each rinse and post-fixed for 1 hour in $1 \%$ osmium tetroxide in distilled water. The samples were again rinsed 3 times in distilled water for 5 minutes each rinse and then rehydrated in $0 \%, 50 \%, 70 \%$, $80 \%$ ethanol for 10 minutes, $95 \%$ ethanol with 2 changes within 10 minutes and $100 \%$ ethanol from a newly opened bottle for 3 changes within 15 minutes. The specimens were then placed in propylene oxide for 10 minutes, followed by a 1:1 solution of propylene oxide / resin for a minimum of 1 hour, and a 1:2 propylene oxide / resin from 1 hour to overnight on a rotator. The tissues were embedded in $100 \%$ Epon resin with 2 changes over 2-6 hours. Thick sections were cut and stained with toluidine blue for survey. Using light microscopy, specific areas were selected and thin sections prepared. The thin sections stained with uranyl acetate and lead citrate were viewed with a Philips CM12 transmission electron microscope (Philips Electronics, Amsterdam, The Netherlands).

\section{Results}

MCs incubated with GLCs (amyloidogenic and LCDD-LCs), TLCs and without exposure to LCs.

G but not TLCs induced MC Apoptosis. MCs cultures incubated with TLCs or without LCs exhibited a 3-5\% apoptotic rate (7-10X less than MCs exposed to GLCs) when incubated for 5 minutes, as detected with the annexin V/ propidium iodide assay. The percentage of apoptotic cells in MCs without incubation with TLCs was about the same (3-5\%). In addition, expression of caspase 3 (Figure 1A), and the release of apoptotic bodies extruded from the cells (Figure 1B) confirmed activation of the apoptotic pathways in the MCs incubated with GLCs.

\section{Repair of damaged mesangium by MSCs: morphological assessment}

MSCs appeared as small cells exhibiting minimal amounts of cytoplasm and consequently displaying a high nuclear to cytoplasmic ratio, readily appreciable at the light microscopic level (Figure 2A and B) and were labeled with CD44 (Figure 2C) and CD56. Viewed by electron microscopy, their cytoplasm had few organelles, mainly ribosomes and polyribosomes admixed with rather few cisternae of rough endoplasmic reticulum and scattered mitochondria (Figure $3 \mathrm{~A}$ and $\mathrm{B}$ ). Due to their morphological characteristics they could be easily identified in the $6 \mathrm{D}$ and ex vivo platform systems by light and even better, ultrastructurally. As they differentiated into MCs they acquired 
Citation: Herrera GA, Teng J, Liu X, Zhang Y, Turbat-Herrera EA (2014) Mesenchymal Stem Cells in Mesangial Repair in a Model of Immunoglobulin Light Chain-Mediated Mesangial Injury. J Stem Cell Res Ther 4: 215. doi:10.4172/2157-7633.1000215

Page 5 of 12
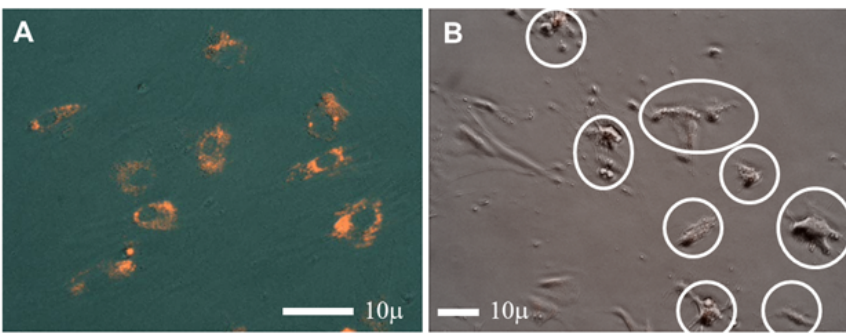

Figure 1: MCs growing as monolayers. Glomerulopathic LCs induce MC apoptosis demonstrated by caspase 3 staining $(A)$ and phase contrast microscopy (B) at 28 hours post initial incubation with LCs. A-X400; B-X250- Immunohistochemistry for caspase 3 in 6D live cell platform MCs incubated with MCs and tested for caspase 3 activity (magic red) showing intracytoplasmic staining indicative of activation of apoptotic pathway. B. MCs releasing apoptotic bodies (circles)

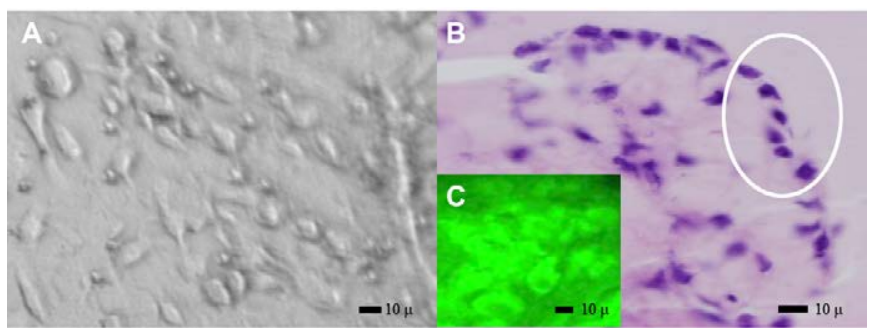

Figure 2: MSCs grown as monolayer and on Matrigel. A. Phase contrast microscopy X350; B. light microscopy X300; C. MSCs labeled with $\mathrm{PKH}$ green $X 500$. MSCs are small primitive-appearing cells with scanty cytoplasm, as seen with phase contrast and light microscopy (circle) (A,B). Labeling of MSCs membranes with PKH-green (C).
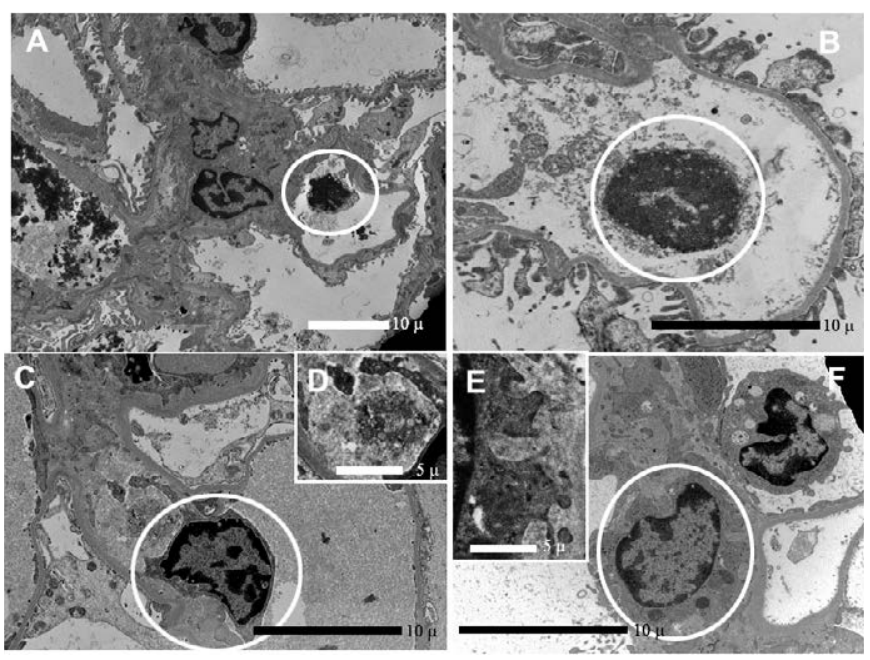

Figure 3: Ex-vivo kidney perfusion platform. Up to 48 hours post initial treatment with glomerulopathic LCs. RMCs interacting with damaged mesangium. Transmission electron microscopy, uranyl acetate and lead citrate stain AX 7000; BX17500; X7000; DX14000; EX15500; FX17500. A and B- MSCs in glomerular capillary lumina (circle A). The stem cells are small, exhibit a large nuclear to cytoplasmic ratio and minimal amounts of cytoplasm with few organelles (circle B). MSCs identify and approach the damaged mesangial area, embracing it with cytoplasmic extensions (C) (circle) and eventually incorporate themselves into the mesangium (E, $F$ circle) where they proceed to clear debris and eventually differentiate into mesangial cells acquiring more cytoplasm, intracytoplasmic myofilaments, and attachment plaques at their periphery $(\mathrm{E})$. rather abundant cytoplasm exhibiting bundles of myofilaments with spindle densities or dense bodies and attachment plaques at their cell membranes (Figure $3 \mathrm{C}-\mathrm{F}$ ).

\section{6-D Live cell culture platform}

MCs grown on Matrigel and incubated in wells with AL-amyloid LCs engaged in the production of amyloid forming crevices on the Matrigel (Figure 4A) while the ones incubated with LCDD-LCs formed nodules containing excess extracellular matrix material (Figure 4C) surrounded by MCs. Control MCs were incubated with TLCs and grew as a single layer on top of the Matrigel. Matrigel remained intact.

The MSCs were attracted to the sites of injury where either amyloid deposits or deposits of extracellular matrix rich in tenascin were present (Figures 4B and D). Pre-incubation of the MCs treated with the GLCs with curcumin prior to addition of the MSCs increased the number of MCs attracted to the affected areas (Figure 5A-C). Once the MSCs arrived to the sites of injury they proceeded to clean the apoptotic cellular elements and the deposited fibrillary material. Fragments of apoptotic MCs and the fibrillary material were phagocytosed by the MSCs (Figure 6). It was impossible for the MSCs to dispose of the excess extracellular matrix present (Figure 7). However, when preincubated with curcumin, the process of phagocytosing extracellular matrix was facilitated and the MSCs could destroy and dispose of the excess extracellular matrix in the form of mesangial nodules efficiently (Figure 8 ). The details of these processes were clearly depicted with the sequential photos obtained. The different steps of these processes were captured permitting clear appreciation of the events taking place $[42,43]$ (Figures 7 and 8 ).

Coculture of MCs growing on matrigel incubated with LCDD, Al \& MCN LCs and then with MSCs / labeling with muscle specific actin, smoothelin, and CD68

MCs were labeled with muscle specific actin and CD68 and MSCs with CD44. MCs incubated with amyloidogenic LCs engaged in amyloid formation (Figure 9A) while MCs incubated with LCDDLCs formed well defined nodules with increased matrix (Figure 9B
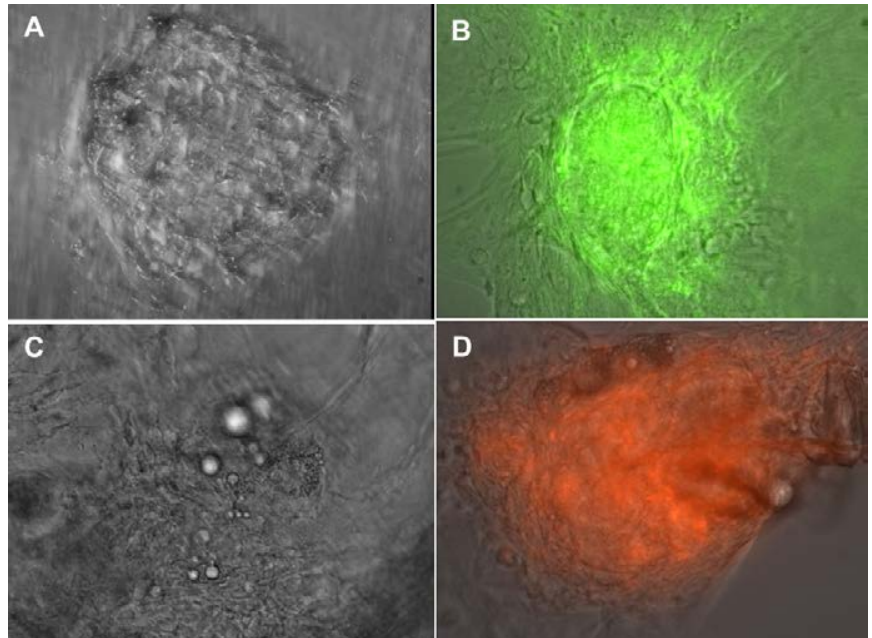

D

Figure 4: MCs growing on Matrigel incubated with LCDD and amyloidogenic LCs for 4 days. A,B-Phase contrast microscopy. AX750; BX750; C D-Mesenchymal stem cells marked with fluorescent PKH green (C) and D with Magic Red. CX750, DX750. MCs incubated with LCDD-LC form mesangial nodules while MCs incubated with amyloidogenic LCs engage in the formation of amyloid. A,B-MSCs migrate to sites of damage $(C, D)$. 
Citation: Herrera GA, Teng J, Liu X, Zhang Y, Turbat-Herrera EA (2014) Mesenchymal Stem Cells in Mesangial Repair in a Model of Immunoglobulin Light Chain-Mediated Mesangial Injury. J Stem Cell Res Ther 4: 215. doi:10.4172/2157-7633.1000215
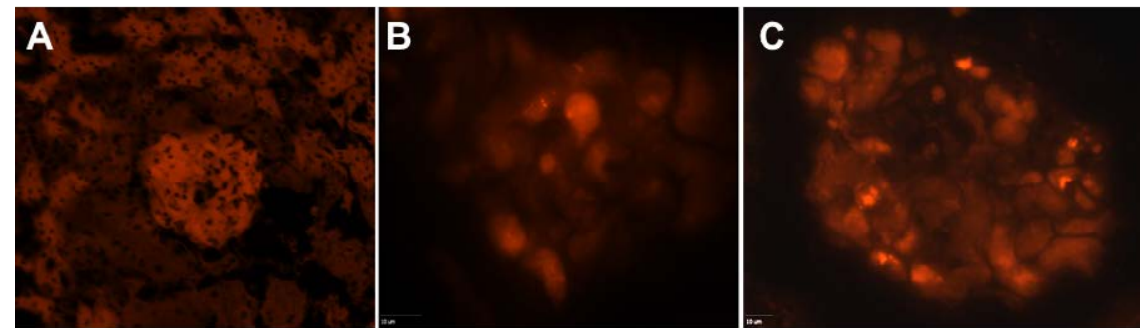

Figure 5: Ex-vivo kidney perfusion platform. RMSCs delivered into glomeruli, eventually migrating into mesangial areas where injury is detected. A- X250- Glomerulus showing MSCs in mesangial areas. B- MSCs in mesangium (no curcumin); C- MSCs in mesangium after curcumin treatment (observation for 48 hours post-treatment with glomerulopathic LCs and then injection of MSCs). AX350; B and CX750- Overall view of glomerulus with MSCs. The number of RMSCs into sites of injury is markedly increased when curcumin is administered before RMSCs are injected through the renal artery (compare B with C).
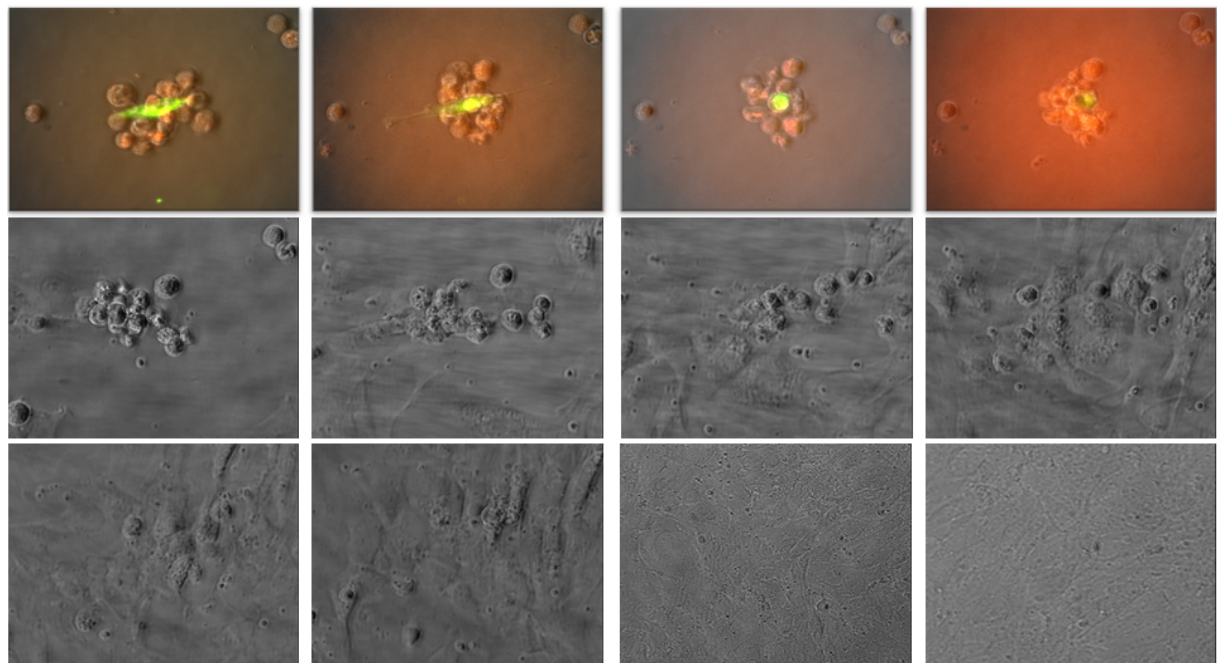

Figure 6: $6 \mathrm{D}$ live MC culture platform. Sequence of events- RMSCs incubated with MCs previously incubated with amyloidogenic LC. MCs labeled with PKH- green fluorescence (X350, all figures). RMSCs dispose of apoptotic MCs (green labeled) by phagocytosing them and then proceed to differentiate acquiring cytoplasm and laying down new matrix.
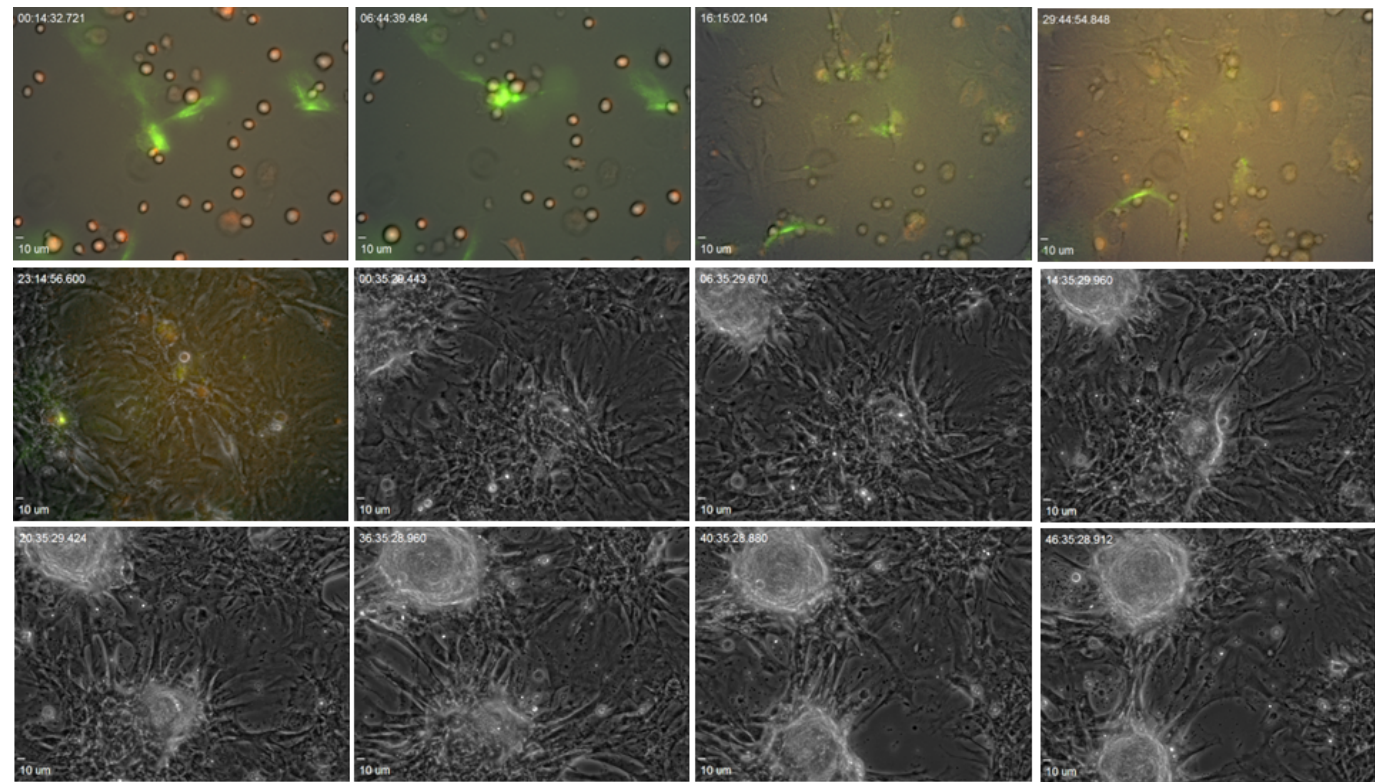

Figure 7: $6 \mathrm{D}$ live MC culture platform. Two weeks observation of events when MCs are incubated with LCDD- LC and then with RMSCs. Note the persistence of mesangial nodules that cannot be disposed of by the MSCs (at the end of the sequence shown). 
Citation: Herrera GA, Teng J, Liu X, Zhang Y, Turbat-Herrera EA (2014) Mesenchymal Stem Cells in Mesangial Repair in a Model of Immunoglobulin Light Chain-Mediated Mesangial Injury. J Stem Cell Res Ther 4: 215. doi:10.4172/2157-7633.1000215
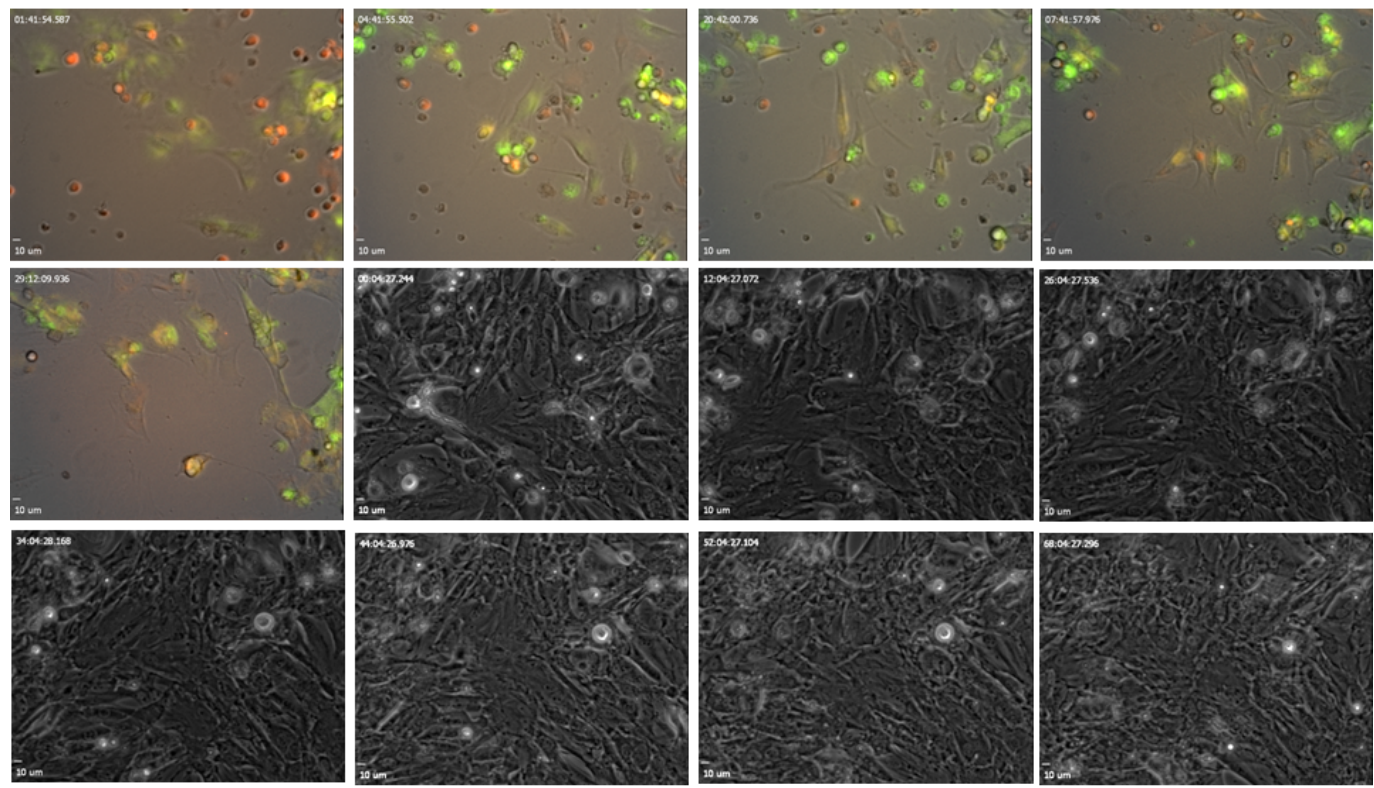

Figure 8: $6 \mathrm{D}$ live MC culture platform. Two weeks observation of events when MCs are pre-treated with curcumin prior to incubation with LCDD-LC and then with RMSCs. Note that MSCs are now able to dispose of the excess extracellular matrix that is formed when MCs are incubated with LCDD-LCs (Compare with Figure 7).
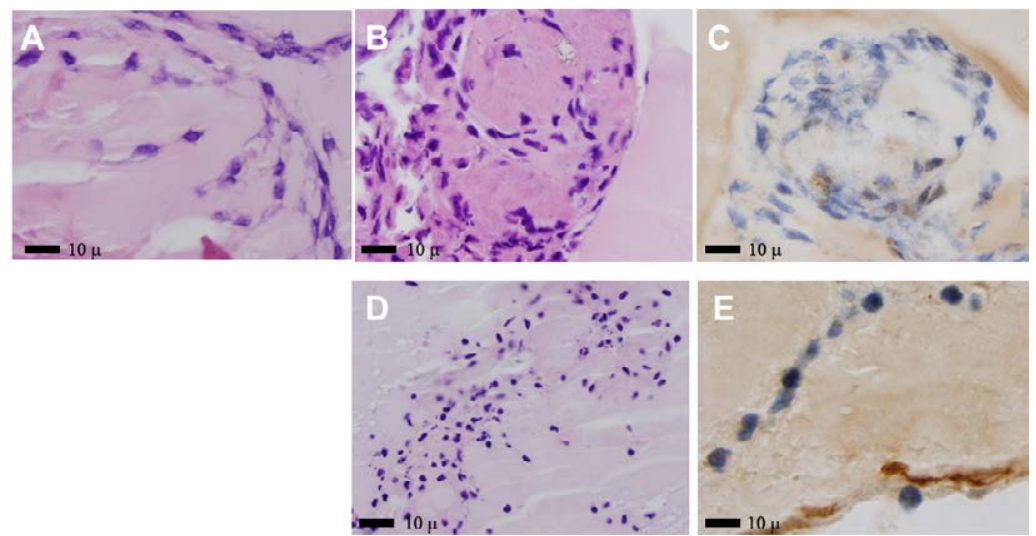

Figure 9: MCs growing on Matrigel platform incubated with amyloidogenic and LCDD LCs followed by introduction of RMSCs. A-C- Hematoxylin and eosin, X500, D- Hematoxylin and eosin, X350; E- Immunohistochemical stain for smooth muscle actin, X350. MCs incubated with amyloidogenic LC formed amyloid (A) and with LCDD-LCs formed nodules with excess extracellular matrix $(B, C)$. Interaction of MCs with MSCs is clearly shown in D. Apoptotic MCs are eventually replaced by MSCs which differentiate into MCs expressing muscle specific actin in their cytoplasm (E).

and C). MSCs were immediately attracted to the sites of injury where they colocalized with MCs, some obviously apoptotic, and avidly interacted with the remaining, often apoptotic MCs (Figure 9D). The MSCs eventually replaced the mesangial cells by eliminating apoptotic ones and proceeded to clean up the damaged areas. MSCs eventually acquired more cytoplasm and differentiated by acquiring features of MCs (Figure 9E).

The apoptotic MC reflected a macrophage phenotype (stained for CD68) when incubated with amyloidogenic LCs, and lost their smooth muscle differentiation (became negative for muscle specific actin, desmin, and smoothelin) and when co-cultured with MSCs, these which initially lacked smooth muscle markers, expressed smoothelin and muscle specific actin as they acquire more cytoplasm and engaged in the repair of the damaged mesangial areas (Figure 10A-E). Interestingly, MCs incubated with LCDD-LCs also showed decreased expression of smooth muscle markers but never lost them entirely while they did not stain for CD68. When co-cultured with MSCs, the MSCs behaved similarly as those co-cultured with MCs incubated with amyloid forming LCs, eventually expressing large amounts of smoothelin and muscle specific actin as they engaged in the repair of the injured mesangium.

\section{Ex vivo kidney perfusion platform}

This platform clearly monitored how MSCs perfused through the renal artery interacted with the affected mesangial areas of kidneys perfused with GLCs by migrating to those areas where mesangial alterations were clearly evident (Figure 11A-G). MSCs were first identified in glomerular capillaries (Figure 2F). Upon arrival to the mesangial areas with damage (Figure $11 \mathrm{G}$ ), they proceeded to phagocytose apoptotic MCs and debris. 
Citation: Herrera GA, Teng J, Liu X, Zhang Y, Turbat-Herrera EA (2014) Mesenchymal Stem Cells in Mesangial Repair in a Model of Immunoglobulin Light Chain-Mediated Mesangial Injury. J Stem Cell Res Ther 4: 215. doi:10.4172/2157-7633.1000215
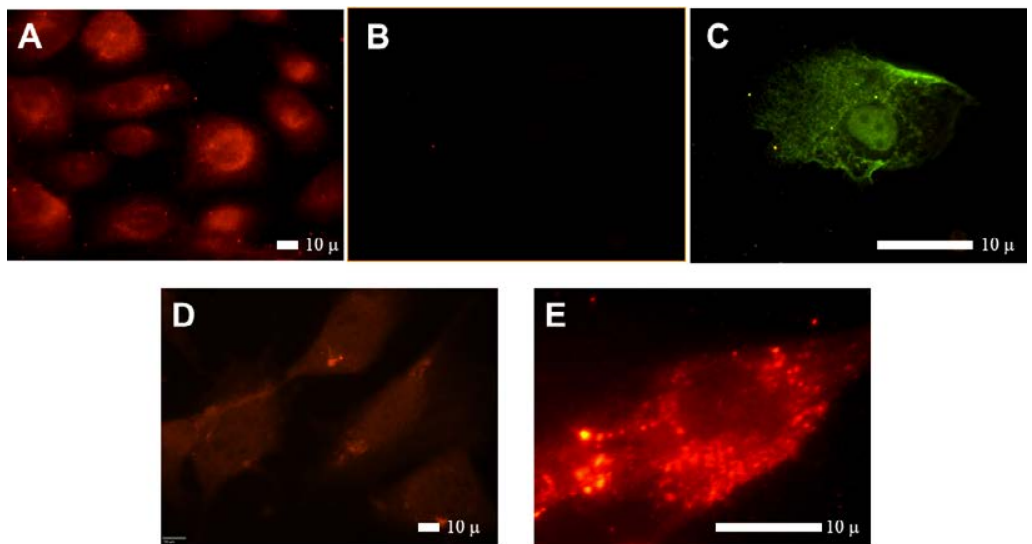

Figure 10: MCs grown as monolayers MC Phenotypic transformation and differentiation of MSCs into mature MCs. MCs incubated with amyloidogenic and LCDD LCs and then with RMSCs- X250 all figures. MCs incubated with amyloidogenic LC undergo transformation from a smooth muscle phenotype (expressing smoothelin-A) to a macrophage one, loosing smoothelin and acquiring CD68 in their cytoplasm (B and C). In contrast, RMSCs lack smoothelin (D), and acquire it after they differentiate into $\mathrm{MCs}(\mathrm{E})$.
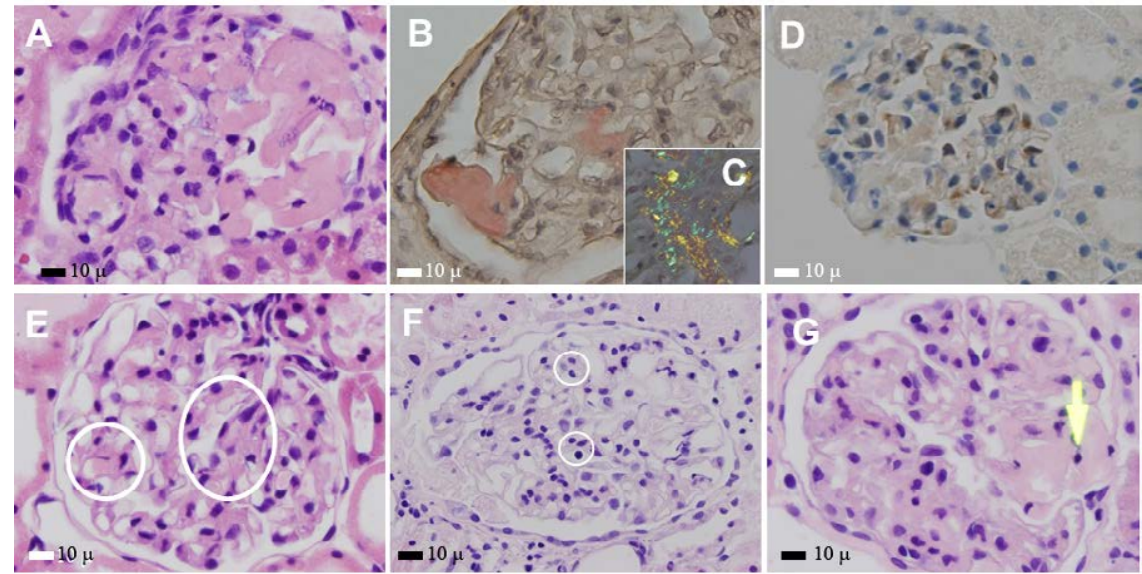

Figure 11: Ex-vivo kidney perfusion platform. Injection of amyloidogenic (A-D) and LCDD (E)-LCs via renal artery followed by injection of MSCs (F,G) through renal artery. AX350, Hematoxylin and eosin stain; BX350, Congo red stain; CX500, polarization of Congo red stained section; DX350, immunohistochemistry stain for smooth muscle actin; EX350- Hematoxylin and eosin stain; FX350- Hematoxylin and eosin stain; G-X350- Hematoxylin and eosin stain. Amyloid formation with Congo red staining and apple green birefringence occurring when MCs were incubated with amyloidogenic LCs (A-D) and expanded mesangial areas with extracellular matrix forming small mesangial nodules (E). MSCs in capillary lumina in glomerulus (F) (circles) and migrating to site where amyloid formation (arrow) has occurred in a glomerulus $(G)$ to participate in the repair of the damaged mesangium.

Once the initial cleaning step was completed, they incorporated themselves into the injured mesangial areas, where they acquired more cytoplasm and differentiated into MCs by developing intracellular myofilaments and attachment plaques at the cell surfaces. Once converted, they surrounded the affected matrix and began the process of phagocytosis. The repair process resulted in replacement of the affected mesangium with new MCs and the beginning of the remodeling of the extracellular matrix. These observations were best carried out using transmission electron microscopy to visualize the initial processes associated with the sequence of events (Figure 4), though due to the fact that the kidneys could only be maintained physiologically intact up to 96 hours; the final restructuring of the mesangium could not be appreciated with this platform. Pre-perfusion of curcumin before MSCs were injected significantly increased the number of stem cells that were delivered to the injured mesangial areas (Figure 5) enhancing and accelerating the healing process.

Furthermore, curcumin pre-treatment allowed the RMSCs to effectively dispose of the mesangial nodules formed when MCs were incubated with LCDD-LCs (Figures 7 and 8). The tenascin-rich mesangial nodules were destroyed and a new matrix was laid down.

\section{Discussion}

The damaged mesangium by GLCs exhibits a decrease in functional MCs as a result of apoptosis induced by the LCs, an altered mesangial matrix which in the case of amyloidosis is replaced by amyloid fibrils and in LCDD is expanded as a result of deposition of abnormal, difficult to catabolize matrix proteins such as tenascin, and an absence of growth factors needed for repair such as transforming growth factor- $\beta[1-4,10]$. The normal repair mechanisms cannot effectively remodel the damaged mesangium and progressive renal insufficiency and, eventually, renal failure ensues. This work addresses a novel way to heal the damaged mesangium which can potentially evolve into the clinical arena in the future.

MSCs are very attractive candidates for renal repair and regeneration and, in a more generic way, to protect against kidney failure. MSCs 
exhibit a number of unique characteristics that make them excellent candidates to participate in repair activities. These multipotent cells identify and migrate to sites of injury, possess immunomodulatory functions and do not express blood group or major histocompatibility $(\mathrm{MCH})$ Class II antigens. They also lack stimulatory factors that may be deleterious to the repair process and engage in signaling transduction, a property very important to cross talk with other cells in the renal parenchyma, most importantly in the glomerulus, when glomerular repair is the task at hand. Other important factors to highlight that make these cells the right candidates for glomerular repair / regeneration include that nephrons are of mesenchymal origin and, last but not least, are the fact that stromal cells in general are very important in signaling leading to differentiation into various cell types in glomeruli. The fact that these cells express specific antigens such as CD29, CD44, CD54, CD56, CD73, CD90, and CD105 makes possible their accurate identification and permit to follow their course during the process of repair $[44,45]$. In the work reported, CD44 and CD56 were used to label MSCs. There are specific signals that drive MSCs to differentiate into MCs [46-49].

The role of exogenous MSCs administration for glomerular repair is still poorly understood. Initial experimental studies have cleared and paved the way creating a solid framework to continue exploring repair of the glomerular compartment [50-55].

A study using the anti-Thy model of renal damage which results in mesangiolysis concluded that the effect of MSCs in mesangial repair was only a paracrine one and that these stem cells did not convert into MCs [55]. The conclusions reached in this study have been proven to be inaccurate. Other studies have clearly shown that although paracrine effects may be at play in the repair of the mesangium, MSCs differentiate into mature MCs and mesangial repair is very much a result of this transdifferentiation [56,57].

The present study supports that the latter is the case, as the MSCs quickly identify the sites of mesangial injury, clear the affected area, and proceed to differentiate into cells with morphologic characteristics of MCs. These transformed MSCs acquired intracytoplasmic smoothelin and muscle specific actin, typical of MCs and exhibited ultrastructural features characteristic of mature MCs. Depending on the platform used; the various phases of this process were displayed. The $6 \mathrm{D}$ platform was the only one that permitted evaluation of the entire process of mesangial repair by MSCs, as the other platforms did not allow observations long enough to evaluate the entire sequence of events.

Similar results were obtained by Wong et al in their studies $[56,57]$. Differentiation of MSCs into MCs has been shown by Wong et al in a murine model and when cocultured with injured MCs. This manuscript addresses the efficacy of this process and also highlights the challenges that occur. In one of these studies they noted differentiation of MSCs into MCs when cocultured with injured MCs [57]. These newly formed MCs had mesangial cell morphology and contracted in response to angiotensin II and concomitantly, the involved cells changed from expressing MSCs to mesangial cell markers.

The "altered" mesangial matrix may not only be destroyed but it may be also changed as a result of accumulation of matrix proteins not normally present in the mesangium, depending on the injurious agent and the response of the MCs and matrix to it. The effect of curcumin in potentiating "healing" of the damaged mesangium, especially when increased matrix is present as a result of several combined peculiar actions. It has been shown in our models that curcumin enhances the migration of MSCs into the damaged mesangial areas. This by itself enhances the ability of these cells to effect changes towards mesangial "healing". Curcumin also enhances apoptosis [58] helping to clear the way for mesangial repair by MSCs, as was clearly demonstrated in this study. It has also been shown in the literature that curcumin is efficacious in reducing extracellular matrix in keloids which also contain large amounts of abnormal proteins such as tenascin. Curcumin has been demonstrated to inhibit the TGF- $\beta 1 /$ SMAD signal pathway resulting in decreased expression of extracellular matrix proteins in keloids [59]. Excessive production of extracellular matrix in keloids could be blocked and / or rapidly decreased by curcumin. Other curcumin properties that have been proposed include possible metalloproteinase-like activity and ability to cleave integrin-extracellular matrix interactions, both of this making matrix removal easier. In addition, it has been hypothesized that curcumin may "prime" the extracellular matrix for further clearing. While a number of hypothesis have been entertained to explain how curcumin can interact with the abnormal matrix to facilitate its removal by MSCs, a better understanding of the underlying molecular mechanisms involved will greatly enhance the development of potential new therapies.

The current model has provided new insights into how the damaged mesangium can be healed. In mesangial repair, there is initial recruitment of MSCs from the bone marrow to the sites of glomerular injury. MSCs comprise less than $0.01 \%$ of all bone marrow cells; therefore, this potentially important cellular reservoir for glomerular repair is rather limited [60]. This coupled with the fact that native MCs and associated growth factors at the sites of injury are generally decreased and, in some instances, almost completely depleted due to mesangial cell apoptosis induced by the injurious stimulus, makes mesangial repair a challenge that may not be conquered without the participation of exogenous MSCs. Likewise, progenitor stem cells may also play a role in some of these circumstances providing additional help in an effort to repair the damaged glomerulus. Recent studies have demonstrated that the contribution of cells from non-renal sources to repair and regeneration in the kidney is rather minimal and the contribution of existing progenitor cells to glomerular healing also appears limited.

This present study focuses specifically in mesangial repair and the unique research platform permits clear evaluation of the sequence of events at play. Remodeling of the glomerulus in-toto after injury presents a number of additional challenges if the damage goes beyond the mesangium and results in destruction of capillary spaces and in the laid down of sclerotic matrix leading to segmental sclerosis. Using mathematical models, it has been established that more than when more than $50 \%$ of the glomerular tufts become sclerosed, this leads to irreversible glomerular damage which will inevitably progress to global glomerulosclerosis [61]. Once glomerular sclerosis occurs, regeneration of renal capillaries is required [61] and there is a need to eliminate and remodel the extracellular matrix that is part of the scarring glomerular process, as well as replacement of podocytes and basement membranes are essential to reestablish glomerular integrity which will require growth of new capillaries. Glomeruli with less than $50 \%$ sclerosis are capable of developing new capillary loops [62].

Because of the complexity involved in the processes, cross-talk between MSCs which have populated the mesangium and other resident glomerular cells is essential to accomplish this type of more extensive repair / regeneration. Several growth factors need to participate in concert. For example, vascular endothelial growth factor (VEGF) has been shown to ameliorate glomerulosclerosis and to enhance glomerular capillary repair and plays a crucial role in accelerating resolution of experimentally induced glomerular injury that extends 
beyond mesangial damage [61]. Podocytes secrete several growth factors, including VEGF-A and angiopoeitin-1 crucial for normal glomerular endothelial functions. In the process of regeneration of new capillaries, restoration of the functional activities of podocytes becomes very important.

In summary, specific mechanisms involved in glomerular repair and whether administration of exogenous MSCs may be beneficial [63-73], remain incompletely understood but the present study presents clear evidence that mesangial repair is possible. Research to decipher specific molecular mechanisms involved completely so that this information can be used to device new therapeutic avenues to heal damaged glomeruli is on going. Introduction of MSCs into damaged mesangial areas provides a novel way to enhance repair activities and may become an important therapeutic approach to treat diseases characterized by glomerular damage in the future. This exciting research area is quite promising but much work remains to be done.

Preliminary phase I clinical trials have been successfully conducted in humans demonstrating the important role that MSCs may play in tubular repair [74]. Similar trials are needed to evaluate the ability of MSCs to efficaciously participate in glomerular repair [75,76]. One of the challenging aspects to assure that whatever intervention is carried out to control and heal glomerular damage can be sustained until the injurious agent is/are completely eliminated or neutralized.

There are complications associated with stem cell therapies that need to be carefully studied [77]. The plasticity of the MCs reflected in their role in both remodeling and scarring [78] creates concern as to whether MSCs when transformed to MCs may display these dual characteristics as well. Further studies are required to address potential pitfalls of exogenous mesenchymal stem cell therapy [49,53].

Another challenge is how to efficiently deliver the exogenous stem cells into the injured renal compartments [63]. If the MSCs are delivered at random (i.e. by injecting them into the renal parenchyma [34]), these cells may never reach where they are needed for repair, at least in the required amounts. If delivered by a hematogenous route, MSCs may become trapped in the microvasculature before reaching injured sites. Another idea that deserves to be explored is delivery of stem cells with growth factors and cytokines in the form of "cocktails" combined with organ-specific ligands that would make them home specifically in desired injured renal locations when delivered intravascularly or by other convenient routes [63]. Progenitor-cell-based therapies may also possibly develop as a novel tool for the treatment of certain renal diseases [74], but it needs to be further tested to answer basic feasibility and real potential.

\section{References}

1. Teng J, Turbat-Herrera EA, Herrera GA (2007) The role of translational research advancing the understanding of the pathogenesis of light chain (LC)mediated glomerulopathies. Pathol Int 57: 398-412. [PubMed]

2. Keeling J, Teng J, Herrera GA (2004) AL-amyloidosis and light chain deposition disease light chains induce divergent phenotypic transformations of human mesangial cells. Lab Invest 84: 1322-1338. [PubMed]

3. Keeling J, Herrera GA (2005) Matrix metalloproteinases and mesangial remodeling in light chain-related glomerular damage. Kidney Int 68: 15901603. [PubMed]

4. Keeling J, Herrera GA (2009) An in-vitro model of light chain deposition disease. Kidney Int 75: 634-645. [PubMed]

5. Mason RM, Wahab NA (2003) Extracellular matrix metabolism in diabetic nephropathy. J Am Soc Nephrol 14: 1358-1373. [PubMed]

6. Abboud HE (2012) Mesangial cell biology. Exp Cell Res 318: 979-985. [PubMed]
7. Ito T, Suzuki A, Imai E, Okabe M, Hori M (2001) Bone marrow is a reservoir of repopulating mesangial cells during glomerular remodeling. J Am Soc Nephrol 12: 2625-2635. [PubMed]

8. Imasawa T, Utsunomiya Y, Kawamura T, Zhong Y, Megasawa R, et al. (2001) The potential of bone marrow-derived cells to differentiate into glomerular mesangial cells. J Am Soc Nephrol 12: 1401-1409. [PubMed]

9. Stetler-Stevenson WG (1996) Dynamic of matrix turnover during pathologic remodeling of the extracellular matrix. Am J Pathol 148: 1345-1350. [PubMed]

10. Herrera GA (2006) Plasticity of mesangial cells: A basis for understanding pathological alterations. Ultrastruct Pathol 30: 471-479. [PubMed]

11. Sugimoto H, Mundel TM, Sund M, Xie L, Cosgrove D, et al. (2006) Bonemarrow-derived stem cells repair basement membrane collagen defects and reverse genetic kidney disease. Proc Natl Acad Sci USA 103: 7321-7326. [PubMed]

12. Prodromidi El, Poulsom R, Jeffery R, Roufosse CA, Pollard PJ, et al (2006) Bone marrow-derived cells contribute to podocyte regeneration and amelioration of renal disease in a mouse model of Alport Syndrome. Stem Cells 24: 2448-2455. [PubMed]

13. Bryder D, Rossi DJ, Weissman IL (2006) Hematopoietic stem cells. The paradigm tissue-specific stem cell. Am J Pathol 169: 338-346. [PubMed]

14. Chapel A, Bertho JM, Bensidhoum M, Fouillard L, Young RG, et al. (2003) Mesenchymal stem cells home to injured tissues when co-infused with hematopoietic cells to treat a radiation-induced multi-organ failure system. $J$ Gene Med 5: 1028-1038. [PubMed]

15. Sagrinati C, Netti GS, Mazzinghi B, Lazzeri E, Liotta F, et al. (2006) Isolation and characterization of multipotent progenitor cells from the Bowman's capsule of adult human kidneys. J Am Soc Nephrol 17: 2443-2456. [PubMed]

16. Gupta S, Verfaillie C, Chmielewski D, Kren S, Eidman K, et al. (2006) Isolation and characterization of kidney-derived stem cells. J Am Soc Nephrol 17: 30283040. [PubMed]

17. Appel D, Kershaw DB, Smeets B, Yuan G, Fuss A, et al. (2009) Derivation of podocytes from the parietal cell compartment. J Am Soc Nephrol 20: 333-343. [PubMed]

18. Ronconi E, Sagrinati C, Angelotti ML, Lazzer E, Mazzinghi B, et al. (2009) Regeneration of glomerular podocytes by human renal progenitors. J Am Soc Nephrol 20: 322-332. [PubMed]

19. Little M, Bertram JF (2009) Is there such a thing as a renal stem cell? J Am Soc Nephrol 20: 2112-2117. [PubMed]

20. Humphreys BD (2009) Slow-cycling cells in renal papilla: Stem cells awaken? J Am Soc Nephrol 20: 2277-2279. [PubMed]

21. Oliver JA, Kinakis FH, Friedlander J, Sampogna RV, Martens TP, et al. (2009) Proliferation and migration of label-retaining cells of the kidney papilla. J Am Soc Nephrol 20: 2315-2327. [PubMed]

22. Romagnani $P$ (2011) Parietal epithelial cells: Their role in health and disease Switzerland.

23. Bussolati B, Bruno S, Grange C, Buttiglieri S, Deregibus MC, et al. (2005) Isolation of renal progenitor cells from adult human kidney. Am J Pathol 166: 545-555. [PubMed]

24. Maeshima A, Yamashita S, Nojima Y (2003) Identification of renal progenitorlike tubular cells that participate in the regeneration processes of the kidney. $J$ Am Soc Nephrol 14: 3138-3146. [PubMed]

25. Dekel B, Zangi L, Shezen E, Reich-Zeliger S, Eventov-Friedman S, et al (2006) Isolation and characterization of nontubular sca-1+lin- multipotent stem/ progenitor cells from adult mouse kidney. J Am Soc Nephrol 17: 3300-3314. [PubMed]

26. Kitamura S, Yamasaki Y, Kinomura M, Sugaya T, Sugiyama H, et al. (2005) Establishment and characterization of renal progenitor like cells from S3 segment of nephron in rat adult kidney. FASEB J 19: 1789-1797. [PubMed]

27. Romagnani $P$ (2011) Renal progenitor of Bowman's capsule and its tubular brothers. Am J Pathol 178: 490-493. [PubMed]

28. Lindgren D, Boström AK, Nilsson K, Hansson J, Sjölund J, et al. (2011) Isolation and characterization of progenitor-like cells from human renal proximal tubules. Am J Pathol 178: 828-837. [PubMed]

29. Appel D, Kershaw DB, Smeets B, Yuan G, Fuss A, et al. (2009) Recruitment 
Citation: Herrera GA, Teng J, Liu X, Zhang Y, Turbat-Herrera EA (2014) Mesenchymal Stem Cells in Mesangial Repair in a Model of Immunoglobulin Light Chain-Mediated Mesangial Injury. J Stem Cell Res Ther 4: 215. doi:10.4172/2157-7633.1000215

Page 11 of 12

of podocytes from glomerular parietal epithelial cells. J Am Soc Nephrol 20: 333-343. [PubMed]

30. Ronconi E, Sagrinati C, Angelotti ML, Lazzeri E, Mazzinghi B, et al. (2009): Regeneration of glomerular podocytes by human renal progenitors. J Am Soc Nephrol 20: 322-332. [PubMed]

31. Morigi M, Imberti B, Zoja C, Corna D, Tomasoni S, et al. (2004) Mesenchymal stem cells are renotropic: Helping to repair the kidney and improve function in acute renal failure. J Am Soc Nephrol 15: 1794-1804. [PubMed]

32. Herrera MB, Bussolati B, Bruno S, Fonsato V, Romanazzi GM, et al. (2004) Mesenchymal stem cells contribute to the renal repair of acute tubular epithelial injury. Int J Mol Med 14: 1035-1041. [PubMed]

33. Ninichuk V, Gross O, Segerer S, Hoffman R, Radomska E, et al. (2006) Multipotent mesenchymal stem cells reduce interstitial fibrosis but do not delay progression of chronic renal disease in collagen 4A3-deficient mice. Kidney In 70: 121-129.

34. Yokoo T, Kawamura T, Kobayash E (2008) Stem cells for kidney repair: usefu tool for acute renal failure. Kidney Int 74: 847-849. [PubMed]

35. 3. Masuda Y, Shimizu A, Mori T, Ishiwata T, Kitamura H, et al. (2001) Vascular endothelial growth factor enhances glomerular capillary repair and accelerates resolution of experimentally induced glomerulonephritis. Am J Pathol 159: 599608. [PubMed]

36. Uchimura H, Marumo T, Takase O, Kawachi H, Shimizu F, et al. (2005) Intrarenal injection of bone marrow-derived angiogenic cells reduces endothelial injury and mesangial cell activation in experimental glomerulonephritis. J Am Soc Nephrol 16: 997-1004. [PubMed]

37. Sanders PW, Herrera GA, Galla JH (1987) Human Bence Jones toxicity in rat proximal tubule epithelium. Kidney Int 32: 851-861. [PubMed]

38. Harper PA, Robinson JM, Hoover RL, Wright TC, Karnovsky MJ (1984) Improved methods for culturing rat glomerular cells. Kidney Int 26: 875-880. [PubMed]

39. Griffiths G, Simons K, Mellman I, Kornfeld S (1968) The mannose 6-phosphate receptor and biogenesis of lysosomes. 52: 329-241. [PubMed]

40. Teng J, Herrera GA (2007) Ex-vivo perfusion model to study pathogenesis of light chain-mediated glomerulopathies (Abstract). Lab Invest 87: 275A.

41. Teng J, Herrera GA (2008) Mesangial amyloid formation in an isolated rat/ kidney perfusion model: A new model to study renal amyloidogenesis. CRC Press, Taylor and Francis Group, Boca Raton, New York.

42. Herrera GA, Turbat-Herrera EA, Teng J (2010) Repair of damaged mesangium by rat mesenchymal stem cells using a $6 \mathrm{D}$ living cell model (Abstract). Amyloid 18: 29-31. [PubMed]

43. Teng J, Herrera GA (2008) Replacement of injured rat mesenchymal mesangial cells by glomerulopathic light chains (GLCs) by rat mesenchymal cells (RMSCs): A 6D living cell model of mesangial repair (Abstract). J Am Soc Nephrol 19: 435A.

44. Al-Awqati Q, Oliver JA (2002) Stem cells in the kidney. Kidney Int 61: 387-395. [PubMed]

45. Chen J, Park H-C, Addabbo F, Ni J, Pelger E, et al. (2008) Kidney-derived mesenchymal stem cells contribute to vasculogenesis, angiogenesis, and endothelial repair. Kidney Int 74: 879-889. [PubMed]

46. Zerbini G, Piemonti L, Maestroni A, Dell'Antonio G, Bianchi G (2006) Stem cells and the kidney: A new therapeutic tool? J Am Soc Nephrol 17: S123-S126. [PubMed]

47. Zhu H, Mitsuhashi N, Klein A, Barsky LW, Weinberg K, et al. (2006) The role of hyaluronan CD44 in mesenchymal stem cell migration in the extracellular matrix. Stem Cells 24: 928-935. [PubMed]

48. Herrera MB, Bussolati B, Bruno S, Morando L, Mauriello-Romanazzi G, et al (2007) Exogenous mesenchymal stem cells localize to the kidney by means of CD44 following acute tubular injury. Kidney Int 72: 430-441. [PubMed]

49. Reilly GC, Engler AJ (2010) Intrinsic extracellular matrix properties regulate stem cell differentiation. J Biomech 43: 55-62. [PubMed]

50. Togel FE, Westenfelder C (2010) Mesenchymal stem cells: a new therapeutic tool for AKI. Nephrol 6: 179-183. [PubMed]

51. Hopkins C, Li J, Rae F, Little MH (2009) Stem cell options for kidney disease. J Pathol 217: 265-281. [PubMed]
52. Yokote S, Yamanaka S, Yokoo T (2012) De novo kidney regeneration with stem cells. J Biomed Biotechnol 2012: 453519. [PubMed]

53. Nagy A, Quaggin SE (2010) Stem cell therapy for the kidney: A cautionary tale J Am Soc Nephrol 21: 1070-1072. [PubMed]

54. Fang T-C, Alison MR, Cook HT, Jeffery R, Wright NA, et al. (2005) Proliferation of bone marrow-derived cells contributes to regeneration after folic acidinduced acute tubular injury. J Am Soc Nephrol 16: 1723-1732. [PubMed]

55. Kunter U, Rong S, Djuric Z, Boor P, Müller-Newen G, et al. (2006) Transplanted mesenchymal stem cells accelerate glomerular healing in experimental glomerulonephritis. J Am Soc Nephrol 17: 2202-2212. [PubMed]

56. Wong CY, Cheong SK, Mok PL, Leong CF (2008) Differentiation of human mesenchymal stem cells into mesangial cells in post-glomerular injury murine model. Pathology 40: 52-57. [PubMed]

57. Wong CY, Tan EL, Cheong SK (2014) In vitro differentiation of mesenchymal stem cells into mesangial cells when co-cultured with injured mesangial cells. Cell Biol Int 38: 497-501. [PubMed]

58. Chen YF, Chung JG (2006) Curcumin-induced cell cycle arrest and apoptosis in human acute promyelocytic leukemia $\mathrm{H}-60$ cells with MMP changes and caspase-3 activation. Anticancer Res 26: 4361-4371. [PubMed]

59. Hsu Y-C, Chen M-J, Yu Y-M, Ko S-Y, Chang C-C (2010) Suppression of TGF- $\beta$ / SMAD pathway and extracellular matrix production in primary keloid fibroblasts by curcuminoids: its potential therapeutic use in the chemoprevention of keloid. Arch Derm Res 302: 717-724. [PubMed]

60. Poulsom R, Forbes SJ, Hodivala-Dilke K, Ryan E, Wyles S, et al.(2001) Bone marrow contributes to renal parenchymal turnover and regeneration. J Patho 195: 229-235. [PubMed]

61. Fogo A (2001) Progression and potential regression of glomerulosclerosis Kidney Int 59: 804-819. [PubMed]

62. Adamczak M, Gross ML, Amann K, Ritz E (2004) Reversal of glomerula lesions requires coordinated restructuring of glomerular microvasculature. $J$ Am Soc Nephrol 15: 3063-3072. [PubMed]

63. Herrera GA, Turbat-Herrera EA, Teng J (2011) Glomerular repair: Current status and future expectations. In Experimental models for renal diseases: Pathogenesis and diagnosis. S. Karger A.G., Basel, Switzerland.

64. Rookmaaker MB, Smith AM, Tolboom H, van't Wout K, Martens AC, et al. (2003) Bone-marrow-derived cells contribute to glomerular endothelial repair in experimental glomerulonephritis. Am J Pathol 163: 553-562. [PubMed]

65. Romagnani, P (2011) Kidney regeneration: any prospects? S Karger AG Basel, Switzerland.

66. Asnaghi V, Ferrari G, Rastaldi MP, Gabellini D, Dell'Antonio G, et al. (2004) Bone marrow-derived stem cells repopulate glomerular and tubular kidney components. Effects of hyperglycemia (Abstract). J Am Soc Nephrol 15: 29.

67. Poulsom R, Alison MR, Cook T, Jeffery R, Ryan E, et al. (2003) Bone marrow stem cells contribute to healing of the kidney. J Am Soc Nephrol 14: S48-S54 [PubMed]

68. LeBleu V, Sugimoto H, Mundel TM, Gerami-Naini B, Finan E, et al. (2009) Stem cell therapies benefit Alport's syndrome. J Am Soc Nephrol 20: 2359-2370. [PubMed]

69. Bussolati B, Hauser PV, Carvalhosa R, Camussi G (2009) Contribution of stem cells to kidney repair. Curr Stem Cell Res Ther 4: 2-8. [PubMed]

70. Vigneau C, Polgar K, Striker G, Elliott J, Hyink D, et al. (2007) Mouse embryonic stem cell-derived embryoid bodies generate progenitors that integrate long term into renal proximal tubules in-vivo. J Am Soc Nephrol 18: 1709-1720. [PubMed]

71. Imai E, Ito T (2002) Can bone marrow cells differentiate into renal cells? Pediat Nephrol 17: 790-794. [PubMed]

72. Ross EA, Williams MJ, Hamazaki T, Terada N, Clapp WL, et al. (2009) Embryonic stem cells proliferate and differentiate when seeded into kidney scaffolds. J Am Soc Nephrol 20: 2338-2347. [PubMed]

73. Ito T, Suzuki A, Okabe M, Imai E, Hori M (2001)Application of bone marrowderived stem cells in experimental nephrology. Exp Nephrol 9: 444-450. [PubMed]

74. Busolati B, Hauser P-V, Carvalhosa R, Camussi G (2009) Contributions of stem cells to kidney repair. Curr Stem Cell Res Ther 4: 2-8. [PubMed] 
Citation: Herrera GA, Teng J, Liu X, Zhang Y, Turbat-Herrera EA (2014) Mesenchymal Stem Cells in Mesangial Repair in a Model of Immunoglobulin Light Chain-Mediated Mesangial Injury. J Stem Cell Res Ther 4: 215. doi:10.4172/2157-7633.1000215

Page 12 of 12

75. Rabelink TJ, van Kooten C (2006) Stem cell therapy for glomerular disease. J Am Soc Nephrol 17: 2086-2088. [PubMed]

76. Caplan A (2009) Why are MSCs therapeutic? New data: new insight. J Pathol 217: 318-324. [PubMed]

77. Thirabanjasak D, Tantiwongse K, Thorner PS (2010) Angiomyeloproliferative lesions following autologous stem cell therapy. J Am Soc Nephrol 21: 12181222. [PubMed]

78. El Nahas AM (2003) Plasticity of mesangial cells: Role in kidney remodeling and scarring. Kidney Int 64: 1553-1563. [PubMed] 